\title{
Does Motivation Predict Persistence and Academic Success?
}

\author{
Kelli D. Whittington \\ Division of Nursing, McKendree University, Lebanon, USA \\ Email: kdwhittington@mckendree.edu
}

Received 25 November 2014; revised 21 December 2014; accepted 6 January 2015

Copyright (C) 2015 by author and Scientific Research Publishing Inc.

This work is licensed under the Creative Commons Attribution International License (CC BY). http://creativecommons.org/licenses/by/4.0/

c) (i) Open Access

\begin{abstract}
This study researches the relationship between motivation and academic success as measured by the Valence, Instrumentality, and Expectancy Scale. Utilizing Vroom's Expectancy Theory as the framework, the research assesses the responses of 375 nurse assistant students in the state of Illinois to evaluate the self-report of the constructs of Vroom's Expectancy theory in relation to their performance on a standardized high stakes test.
\end{abstract}

\section{Keywords}

\section{Motivation, Vroom's Expectancy Theory, Valence, Instrumentality, Expectancy, and Nurse} Assistant

\section{Introduction}

The United States is facing a major dilemma in providing care for the population. With the population aging and living longer, the number of consumers requiring assistance to meet their health care needs is increasing [1] [2]. As this consumer base expands and seeks health care, the current amount of staff trained to provide care is inadequate [3] [4]. One facet of care delivery is met by the certified nurse assistant. Without an adequate workforce of nurse assistants, patient care will not be at an optimal level. In order to provide an adequate workforce of nurse assistants, educational systems must identify factors that assist in recruiting and retaining individuals in nurse assistant training programs. This study explored one facet of supplying qualified individuals into the workforce: the relationship between motivation, as measured by Vroom's Expectancy Theory, and academic achievement. Endeavoring to identify how motivation impacts academic achievement may potentially increase the amount of certified nurse assistants available to assume employment in the state of Illinois within the health care arena, thus positively impacting patient care.

With the aging population noted in the United States to extend through 2020, it is predicted that hospital 
admissions will increase at a rate of 1.23 times faster than population growth. In order to accommodate this surge, staffing levels in US hospitals will have to grow faster than the population [5]. When employment areas are left unfilled in the health care setting, patients are exposed to potentially detrimental situations, such as inappropriate patient to nurse ratio's, which increases the likelihood of errors [6].

Because individuals are living longer, the need for adequately trained health care providers is evolving at a furious pace. Currently, the amount of health care providers is struggling to meet the needs of the patient care population. The present deficits are increasing the burden associated with a variety of shortages across several related vocational fields [7]. In order to recruit, train and retain competent nurse assistants, it is essential to identify not only those individuals that are cognitively equipped to be successful in this academic arena, but also the impact motivation has on their academic success. McLaughlin [8] and Newton et al. [9] report the need to ascertain the relationship between motivation and how it relates to student success within their particular career choices. Cheng et al. [10] asserts the need to enhance motivation as a means to bolster student success within the arena of high stakes testing, such as the Nurse Aid Competency Examination. Therefore, it is essential to determine how motivation, as measured by Vroom's Expectancy Theory, leads to academic achievement and provides a qualified workforce of certified nurse assistants for the nation's health care centers.

\section{Background}

O*Net [11] lists nurse assistant as a Bright Outlook occupation, with an estimated $20 \%$ to $28 \%$ job growth for the next decade. Without an available qualified workforce, these positions will not be filled, thus impacting patient care at the bedside.

There is no specific indicator or scientific equation that can accurately predict what makes a student successful in their academic endeavors since many factors play a role in student achievement [12]. Because several factors do exist, educators must consider what best enhances student academic achievement, and when factors associated with student achievement are identified, what measures can be used to foster student retention [13]-[16]. Identifying factors that predispose students to poor academic performance can assist the student and educational institution in providing opportunities for remediation that positively influencing the likelihood of academic achievement [17]-[20]. Being able to foster academic achievement results in providing the workforce with individuals equipped with the skills needed to become successful employees.

One variable that is linked to academic achievement is the motivation level of the student [21]. Motivation exists as an extrinsic force, such as the desire for a certain level of income, and as an intrinsic force, like the desire to better oneself for the sake of personal satisfaction. While faculty, administrators, and family can play an influential role in promoting success by fostering extrinsic motivation, it is essential that the student embrace a sense of intrinsic motivation to fully obtain academic achievement [22].

Understanding the relationship between motivation and academic achievement is critical within the educational arena [10]. By identifying factors that nurture motivation, instructors and administrators within institutions of higher learning may positively influence student academic achievement [23]. Fostering student growth will positively impact the student's ability to attain academic achievement. Faculty must understand that students present to academia with a variety of different expectations, and assisting them to invest in their academic pursuit builds personal and professional growth [24].

By utilizing Vroom's Expectancy Theory [25] to quantify student motivation, it is possible to examine the relationship between motivation and student achievement. Identifying how motivation impacts student achievement may assist recruitment and retention of nurse assistant students.

\section{Theoretical Framework}

There were two purposes of this study. The first purpose was to explore the relationship between the concepts of Vroom's Expectancy Theory. Within the framework of Vroom's Expectancy Theory [25], three components are utilized to describe and quantify motivation. The components are Valence (V), Expectancy (E) and Instrumentality (I). Valence describes the attractiveness of a reward [25]. Expectancy is defined as the individual's belief that his/her action will yield a specific result [25]. Instrumentality is best described as the individual obtaining what he/she earns [26]. The second purpose of this study was to use the quantifiable factor obtained from Vroom's Expectancy Theory as a descriptor of the individual's motivation and describe the individual's ability to attain academic achievement as noted by successful completion of the Illinois Nurse Assistant Training 
Competency Examination. Utilizing Vroom's Expectancy Theory as a framework, Sanchez, Truxillo and Bauer [27] developed the Valence, Instrumentality, Expectancy, Motivation Scale (VIEMS) that quantifies test-taking motivation, specifically as it relates to test performance or academic achievement that leads to vocational employment. Vroom's Expectancy Theory, as measured by the Valence, Instrumentality, Expectancy, Motivation Scale (VIEMS) was utilized as the theoretical framework for the proposed study as it provides an opportunity to ascertain motivation as a quantifiable measure, which can be used to describe the correlational relationships between the variables studied.

\section{Research Question}

What is the relationship between the expectancy of being employed as a certified nurse assistant and the Instrumentality subscale of the Valence, Instrumentality, Motivation Scale?

\subsection{Valence, Instrumentality, Expectancy Motivational Scale}

Building upon the constructs in Vroom’s Expectancy Theory, Sanchez et al. [27] developed an instrument to examine the relationship between the known constructs and an individual's testing performance.

\subsection{Definition of Study Population and Sampling Procedures}

Participants consisted of individuals who have successfully completed a nurse assistant program in the state of Illinois, as approved by the Illinois Department of Public Health (IDPH) and were seeking entry into the Illinois Health Care Registry, which infers the individual's successful completion of the Illinois Nurse Assistant Competency Examination [28]. These individuals take the competency examination at various approved locations across the state of Illinois. The competency examination is available monthly in a paper/pencil format. Approximately 1000 individuals test monthly, with an average of $90 \%$ of candidates passing the competency examination upon their first attempt. Although a fairly low amount of individuals do not pass the examination on their first attempt, program evaluation identifies particular programs to be more susceptible to a higher fail rate than other programs. By identifying what factors impact success upon the competency examination, programs with lower than average pass rates could use this data in their admission process, as well as within their training to enhance the possibility of success for their students.

\subsection{Procedure}

Primary data for this study was obtained via descriptive methodology during one testing opportunity. Prior to survey delivery, the Human Rights Committee at the appropriate university granted permission for use of the survey and the relevant statistical analysis. All nurse assistant students sitting for the Illinois Nurse Assistant Competency Examination in the month of March, $2014(\mathrm{~N}=622)$, received a survey with their Illinois Nurse Assistant Competency Examination, which was monitored by a trained testing proctor. They were asked to complete the survey via a letter provided within the testing booklets; completion of the survey was explained to be voluntary, with no penalization if the individual chose to not participate.

\subsection{Research Design}

In this non experimental quantitative study, descriptive statistics were employed to provide description and comparison of various characteristics revealed by the subjects. Logistic regression was utilized to determine the relationships between the dependent variable and chosen independent variables by obtaining correlational coefficients. Logistic regression was utilized as it allows the data to be examined when the variable is "discrete, taking on two or more possible values" [29]. This research and subsequent data analysis is important to the current body of knowledge related to motivation and academic achievement, specifically with the population of nurse assistants.

The second construct, Instrumentality, was evaluated next. This construct was evaluated by utilizing the scores on the next four questions of the survey that was also developed to measure this construct. In measuring Instrumentality, these four questions employed different words to assess similar thoughts related to the relationship of test performance upon job attainment. Per a Likert-type scale where $1=$ strongly agree and $5=$ strongly 
disagree, the majority of respondents chose agree or strongly agree (58.9\%) with the questions designed to measure the individual's perception of their test performance upon future employability as a nursing assistant (Table 1). This response indicates that the test takers report a relationship between their test score and their ability to obtain a job.

\section{Research Question Exploring Expectancy of Being Employed and the Relationship with Instrumentality}

What is the relationship between the Expectancy of being employable as a certified nursing assistant and the instrumentality subscale of the Valence, Instrumentality, Motivation Scale? After the previous findings, this finding proved to be more favorable to the researcher. Yielding a Pearson moment-product correlation coefficient of statistically significance $(r=-0.372, p=0.01)$. This score supports a weak, negative relationship does exist between individual's Expectancy of being employed as a certified nursing assistant and the Instrumentality subscale of the VIEMS (Table 2). The negative score is due to the reverse scoring of the questions ascertaining Instrumentality ( $1=$ strongly agree and $5=$ strongly disagree). This finding suggests that respondent's perceive a relationship between their performance on the Illinois Nurse Assistant Competency Examination and the likelihood of being employed as a certified nursing assistant.

Table 1. Subject's responses on questions $4,5,6$, and 7 assessing instrumentality.

\begin{tabular}{|c|c|c|}
\hline Response Options & Frequency & Percent \\
\hline \multicolumn{3}{|l|}{ Question 4} \\
\hline Strongly Agree & 309 & 82.4 \\
\hline Agree & 37 & 9.9 \\
\hline Neutral & 14 & 3.7 \\
\hline Disagree & 4 & 1.1 \\
\hline Strongly Disagree & 11 & 2.9 \\
\hline \multicolumn{3}{|l|}{ Question 5} \\
\hline Strongly Agree & 222 & 59.2 \\
\hline Agree & 68 & 18.1 \\
\hline Neutral & 47 & 12.5 \\
\hline Disagree & 20 & 5.3 \\
\hline Strongly Disagree & 18 & 4.8 \\
\hline \multicolumn{3}{|l|}{ Question 6} \\
\hline Strongly Agree & 210 & 56 \\
\hline Agree & 70 & 18.7 \\
\hline Neutral & 61 & 16.3 \\
\hline Disagree & 13 & 3.5 \\
\hline Strongly Disagree & 21 & 5.6 \\
\hline \multicolumn{3}{|l|}{ Question 7} \\
\hline Strongly Agree & 142 & 37.9 \\
\hline Agree & 83 & 22.1 \\
\hline Neutral & 86 & 22.9 \\
\hline Disagree & 27 & 7.2 \\
\hline Strongly Disagree & 37 & 9.9 \\
\hline
\end{tabular}


Following the correlational analysis for Research Question Five, linear regression was also utilized. Due to the nature of the questions associated with Instrumentality, the researcher anticipated a regression close to one, which would denote that any variance in Instrumentality could be explained by the likelihood of obtaining a job as a nursing assistant. The finding provided an adjusted $R^{2}$ of 0.136 (Table 3), which suggests that the individual's report of Instrumentality explains a small amount of variance in their response to question 15, which addresses the likelihood of being employed as a nursing assistant.

The present study did demonstrate that a relationship exists between Instrumentality and the individual's perception of the likelihood of job attainment as a certified Nurse assistant. This finding supports prior research conducted by Sanchez, Truxillo, and Bauer [27].

\subsection{Limitations and Conclusions}

This research was not able to find a statistically significant relationship between the constructs of Valence and Expectancy as they relate to motivation and test scores. Also, no statistically significant relationship was identified between motivation as measured aggregately by the VIEMS and test scores. However, the relationships noted did agree with prior research studies supporting the correlation between motivation and academic achievement [27] [30]-[32].

The relationship demonstrated between the variance of Instrumentality and test scores was statistically significant, although the directionality was not anticipated. Several prior research studies share inconclusive responses when examining Instrumentality alone as a construct of motivation [30] [33] [34]. Due to the self-reporting nature of the survey tool, it is difficult to explain this anomaly.

The relationship between the construct of Instrumentality and likelihood of job attainment did show statistical significance. As noted by Sanchez, Truxillo, and Bauer [27], this correlation may be due to the direct relationship the standardized test has on specific career and technical job opportunities. For individuals participating in this research study, it is required to pass the Illinois Nurse Competency Examination in order to register with the Illinois Department of Public Health, making them employable as certified nurse assistants.

Individuals reporting English as a first language scored higher on the Illinois Nurse Assistant Competency Examination (76.73) than the individuals that reported that English was not their first language (73.45). Oliver

\begin{tabular}{|c|c|c|}
\hline Variables & $\begin{array}{l}\text { Question Assessing } \\
\text { Likelihood of Job } \\
\text { Attainment }\end{array}$ & Instrumentality \\
\hline \multicolumn{3}{|l|}{ Question 15} \\
\hline Pearson Correlation & 1 & $-0.372^{* *}$ \\
\hline Sig. (2-tailed) & & 0.000 \\
\hline $\mathrm{N}$ & 375 & 375 \\
\hline \multicolumn{3}{|l|}{ Instrumentality } \\
\hline Pearson Correlation & $-0.372^{* *}$ & 1 \\
\hline Sig. (2-tailed) & 0.000 & \\
\hline $\mathrm{N}$ & 375 & 375 \\
\hline
\end{tabular}

Table 3. Regression between instrumentality and question 15 assessing the likelihood of job attainment.

\begin{tabular}{ccccccccc}
\hline$R$ & $R^{2}$ & Adjusted $R^{2}$ & $\begin{array}{c}\text { Std. Error of } \\
\text { the Estimate }\end{array}$ & $R^{2}$ Change & F Change & df1 & df2 \\
\hline $0.372^{\mathrm{a}}$ & 0.139 & 0.136 & 0.603 & 0.139 & 60.076 & 1 & 373 \\
\hline
\end{tabular}

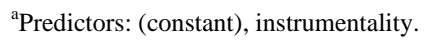


(1995) asserts that the effective teacher has the ability to motivate individuals from diverse backgrounds to achieve as high as their classmates regardless of language or cultural barriers. Although not specifically assessed, identifying nurse assistants and programs that appreciate cultural differences could potentially uncover best practices in current educational delivery system across Illinois.

\subsection{Impact of Research Findings}

Although motivation plays an important role with persistence in academic endeavors, this study found no significant link between motivation, as measured by Vroom's Expectancy Theory, and student academic achievement, as measured by test performance on the Illinois Nurse Assistant Competency Examination. Towards that goal, the findings herein add to the current body of knowledge surrounding motivation within the educational arena by identifying the relationship between Instrumentality, a construct of motivation, and the likelihood of job attainment. The lack of statistical significance could be due to several reasons, two of which are more noticeable. First, the survey tool is completely dependent upon the individual respondent. As noted in prior research, individuals may fake responses on self-reported survey's to enhance their attractiveness or because they believe it to be helpful to them personally [33]. Secondly, individuals may actually have a very positive perception of their performance and how that performance will result in their desires that is in contrast to their academic ability. Due to the timing of the data collection, the majority of test takers were repeating their test due to a prior failure. When an individual is not successful on their first attempt, they must wait one month before they can reapply to sit for the exam again. Theoretically, this time should be spent reviewing the material. However, statistics from the Illinois Nurse Assistant Training Competency Examination Program support that test scores decrease if the individual waits over 64 days from the end of their educational preparation to testing date.

\section{References}

[1] Langer, N. (2008) Integrating Compliance, Communication and Culture: Delivering Health Care to an Aging Population. Educational Gerontology, 34, 385-396. http://dx.doi.org/10.1080/03601270701838381

[2] Peterson, E., Ruble-Davies, C., Elley-Brown, M., Widdowson, D., Dixon, R. and Irving, S. (2012) Who Is to Blame? Students, Teachers and Parents Views on Who Is Responsible for Student Achievement. Research in Education, 86, 1-12. http://dx.doi.org/10.7227/RIE.86.1

[3] Halstead, J. (2012) Advancing Our Nation’s Health: Caring for Our Aging Population. Nursing Education Perspectives, 33, 140. http://dx.doi.org/10.5480/1536-5026-33.3.140

[4] Kinnair, D. (2012) An Aging Population Requires Radical Changes to Nursing Education and Practice. Journal of Holistic Healthcare, 9, 24-26.

[5] Pallin, D., Allen, M., Espinola, J., Camargo, C. and Bohan, J. (2013) Population Aging and Emergency Departments: Visits Will Not Increase, Lengths-of-Stay and Hospitalizations Will. Health Affairs, 32, 1306-1312. http://dx.doi.org/10.1377/hlthaff.2012.0951

[6] Erlen, J. (2001) The Nursing Shortage, Patient Care, and Ethics. Orthopaedic Nursing, 20, 61-65. http://dx.doi.org/10.1097/00006416-200111000-00013

[7] Benson, S. and Dundis, S. (2003) Understanding and Motivating Health Care Employees: Integrating Maslow’s Hierarchy of Needs, Training and Technology. Journal of Nursing Management, 11, 315-320. http://dx.doi.org/10.1046/j.1365-2834.2003.00409.x

[8] McLaughlin, K. (2010) Changing Motivation. Nursing Standard, 51, 61-62.

[9] Newton, J., Kelly, C., Kremser, A., Jolly, B. and Billett, S. (2009). The Motivations to Nurse: An Exploration of Factors amongst Undergraduate Students, Registered Nurses and Nurse Managers. The Journal of Nursing Management, 17, 392-400. http://dx.doi.org/10.1111/j.1365-2834.2008.00945.x

[10] Cheng, P., Li, M. and Su, C. (2011) Attitudes and Motivations of Students Taking Professional Certificate Examinations. Social Behavior and Personality, 39, 1303-1314. http://dx.doi.org/10.2224/sbp.2011.39.10.1303

[11] O*Net (2013) O*Net Online. www.onetonline.org/find/quick?s=nursing+assistants

[12] Dearnley, C. and Matthew, B. (2007) Factors That Contribute to Undergraduate Student Success. Teaching in Higher Education, 12, 377-391. http://dx.doi.org/10.1080/13562510701278740

[13] Adams, C. (2011) Colleges Try to Unlock Secrets to Student Retention. Education Digest, 77, 19-23.

[14] Alarcon, G. and Edwards, J. (2013) Ability and Motivation: Assessing Individual Factors That Contribute to University Retention. Journal of Educational Psychology, 105, 129-137. http://dx.doi.org/10.1037/a0028496 
[15] Popiolek, G., Fine, R. and Eilman, V. (2013) Learning Communities, Academic Performance, Attrition, and Retention: A Four-Year Study. Community College Journal of Research and Practice, 37, 37-41. http://dx.doi.org/10.1080/10668921003744926

[16] Ryan, M. (2013) Improving Retention and Academic Achievement for First-Time Students at a Two-Year College. Community College Journal of Research and Practice, 37, 131-134. http://dx.doi.org/10.1080/10668926.2012.715266

[17] ACTE (2007) Expanding Opportunities: Postsecondary Career and Technical Education and Preparing Tomorrow’s Workforce. A Position Paper.

https://www.acteonline.org/uploadedFiles/Assets_and_Documents/Global/files/Publications/Expanding_Opportunities Postsecondary CTE full.pdf

[18] Bahr, P. (2008) Does Mathematics Remediation Work? A Comparative Analysis of Academic Attainment among Community College Students. Resource for Higher Education, 49, 420-450. http://dx.doi.org/10.1007/s11162-008-9089-4

[19] Carr, S. (2011) NCLEX-RN Pass Rate Peril: One School’s Journey through Curriculum Revision, Standardized Testing, and Attitudinal Change. Nursing Education Perspectives, 32, 384-388. http://dx.doi.org/10.5480/1536-5026-32.6.384

[20] Martorell, P. and McFarlin, I. (2009) Help or Hindrance? The Effects of College Remediation on Academic and Labor Market Outcomes. Society for Research on Educational Effectiveness. (A White Paper)

[21] Lei, S. (2010) Intrinsic and Extrinsic Motivation: Evaluating Benefits and Drawbacks from College Instructors’ Perspectives. Journal of Instructional Psychology, 37, 153-160.

[22] Wong, J., Wong, S. and Mensah, L. (1993) A Conceptual Approach to the Development of Motivational Strategies. Journal of Advanced Nursing, 8, 111-116. http://dx.doi.org/10.1111/j.1365-2648.1983.tb00300.x

[23] Goodman, S., Jaffer, T., Keresztesi, M., Mamdani, F., Mokgatle, D., Musariri, M., Peris, J. and Schulechtler, A. (2011) An Investigation of the Relationship between Students' Motivation and Academic Performance as Mediated by Effort. South African Journal of Psychology, 41, 373-385. http://dx.doi.org/10.1177/008124631104100311

[24] Huett, J., Kalinowski, K., Moller, L. and Huett, K. (2008) Improving the Motivation and Retention of Online Students through the Use of ARCS Based Emails. The American Journal of Distance Education, 22, 159-176. http://dx.doi.org/10.1080/08923640802224451

[25] Vroom, V. (1964) Work and Motivation. Wiley and Sons, New York.

[26] Malloch, D. and Michael, W. (1981) Predicting Student Grade Point Average at a Community College from Scholastic Aptitude Tests and from Measures Representing Three Constructs in Vroom’s Expectancy Theory Model of Motivation. Educational and Psychological Measurement, 41, 1127-1135.

[27] Sanchez, R., Truxillo, D. and Bauer, T. (2000) Development and Examination of an Expectancy-Based Measure of Test Taking Motivation. Journal of Applied Psychology, 85, 739-750. http://dx.doi.org/10.1037/0021-9010.85.5.739

[28] Illinois Department of Public Health (2013) Joint Committee on Administrative Rules, Administrative Code. Health Care Worker Registry. www.idph.state.il.us/nar/home.htm

[29] Hosmer, D., Lemeshow, S. and Sturdivant, R. (2013) Applied Logistic Regression. 3rd Edition, Wiley and Sons, Hoboken. http://dx.doi.org/10.1002/9781118548387

[30] Batlis, N. (1978) Relationships between Locus of Control and Instrumentality Theory Predictor of Academic Performance. Psychological Reports, 43, 239-245. http://dx.doi.org/10.2466/pr0.1978.43.1.239

[31] Harrell, A., Caldwell, C. and Doty, E. (1985) Within-Person Expectancy Theory Predictions of Accounting Students' Motivation to Achieve Academic Success. Accounting Review, 60, 724-735.

[32] Shapira, Z. (1976) Expectancy Determinants of Intrinsically Motivated Behavior. Journal of Personality and Social Psychology, 34, 1235-1244. http://dx.doi.org/10.1037/0022-3514.34.6.1235

[33] Ellingson, J. and McFarland, L. (2011) Understanding Faking Behavior through the Lens of Motivation: An Application of VIE Theory. Human Performance, 24, 322-227. http://dx.doi.org/10.1080/08959285.2011.597477

[34] Simons, J., Dewitte, S. and Lens, W. (2004) The Role of Different Types of Instrumentality in Motivation, Study Strategies, and Performance: Know Why You Learn, so You'll Know What You Learn! British Journal of Educational Psychology, 74, 343-360. http://dx.doi.org/10.1348/0007099041552314 
Scientific Research Publishing (SCIRP) is one of the largest Open Access journal publishers. It is currently publishing more than 200 open access, online, peer-reviewed journals covering a wide range of academic disciplines. SCIRP serves the worldwide academic communities and contributes to the progress and application of science with its publication.

Other selected journals from SCIRP are listed as below. Submit your manuscript to us via either submit@scirp.org or Online Submission Portal.
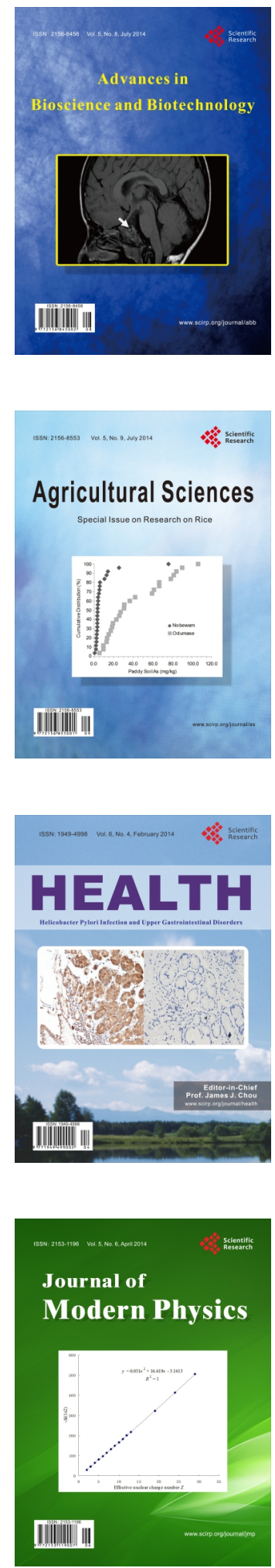
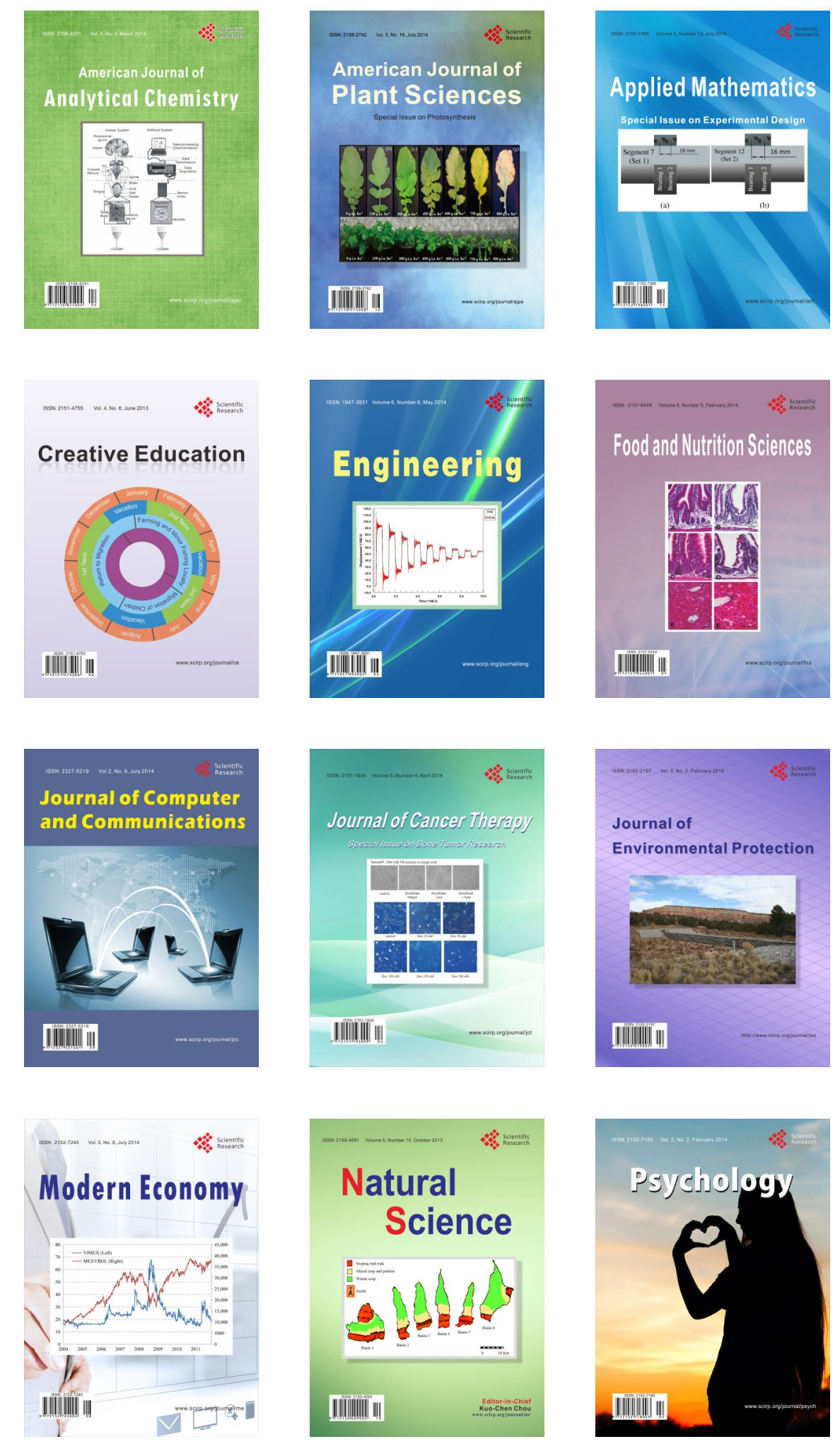